\section{P-195 'PALLIATIVE CRITICAL CARE': TRANSFORMING THE RELATIONSHIP BETWEEN INTENSIVE CARE AND PALLIATIVE CARE}

Helen Crispin, Carol Davis, Robert Chambers, Karen Haynes. Southampton General Hospital, Southampton, UK

\subsection{6/bmjspcare-2018-hospiceabs.220}

Introduction Historically, joint-working between our General Intensive Care Unit (GICU) and Hospital Specialist Palliative Care Team (HSPCT) was restricted to occasional complex cases. In 2013 there was shared recognition that patients, families and staff might benefit from a broader, structured, collaborative approach.

In 2014, we created four hours dedicated intensivist time and enhanced joint working - 'Palliative Critical Care'. In 2016, a weekly combined ward round was established.

Here, we report the impact of this Quality Improvement Initiative on HSPCT activity and place of care.

Methods Retrospective review of HSPCT records between April 2013 and March 2018.

Results Over 300 patients have been seen under this collaborative model since April 2013. Initially, referrals increased from six in $2013 / 14$ to 57 in 2014/15. Continuous development has resulted in sustained year on year increase in referrals; 107 in year $5(2017 / 18)$.

Collaborative working has promoted recognition and treatment of symptoms, and provided an additional layer of support for patients, families and staff. Staff report increased confidence especially in symptom control of actively dying patients. The in-hospital mortality of this patient group is $46 \%-74 \%$ with an ICU mortality of $23 \%$. Patient preferences have been supported; $61.5 \%$ of survivors were discharged home or to a hospice (2017/18). In selected cases discharge has been achieved direct from GICU; seven patients to a hospice and eight to home (2013/14 - 2016/17). Patient, family and staff feedback has been 'excellent'; one relative said ' $I$ had no idea that palliative care and intensive care could work together especially for someone who doesn't have cancer and isn't dying!'

Conclusion Through this Quality Improvement initiative the relationship between our GICU and HSPCT has been transformed from one of occasional interaction to a regular programme of collaborative working resulting in a sustained increase in referrals and supported patient preferences.

\section{P-196 EXPLORING THE QUALITY OF THE DYING AND DEATH EXPERIENCE IN THE EMERGENCY DEPARTMENT: A REVIEW}

\begin{abstract}
1,2Kay McCallum, ${ }^{1,3}$ Debra Jackson, 'Helen Walthall, ${ }^{1}$ Helen Aveyard. 'Oxford Brookes University, Oxford, UK; ${ }^{2}$ Oxford University Hospitals NHS Foundation Trust, Oxford, UK; ${ }^{3}$ University of Technology Sydney, Sydney, Australia
\end{abstract}

10.1136/bmjspcare-2018-hospiceabs.221

Background Patients attend the emergency department (ED) for a variety of reasons. Unfortunately some of these patients will not survive. Little is known about how staff and particularly carers experience being with a dying patient in this setting (Bailey, Murphy \& Porock, 2011; Chan, 2011; Decker, Lee \& Morphet, 2015). The aim of this review was to examine the quality of dying and death in the ED from the perspective of staff and carers.
Method A systematic search of MEDLINE, the Cumulative Index to Nursing and Allied Health Literature (CINAHL), AMED, Magonline (internurse), EMBASE and the Cochrane library was undertaken during February -August 2017. Fourteen articles fit the inclusion criteria (papers published in the English language between 1995-2017) for this review.

Findings and discussion The over-arching theme that emerged is that care in the ED is focused on living not dying. Because the ethos is about saving lives, those whose lives cannot be saved can be marginalised or side-lined, leading to a potentially poorer experience for the relatives and friends (carers) (Bailey, Murphy \& Porock, 2011). Further themes included staff stress and distress, and the difficulty of meeting the needs of the carers in this environment. Carers felt the staff had no time for them and that communication was generally poor (Bailey, Murphy \& Porock, 2011). However, there are minimal studies that asked the views of the carers and this is therefore an area in which further research is needed.

Implications for research and practice Findings suggest that there remains a gap in knowledge around the quality of dying and death in the ED from the perspective of carers of the dying patient. Supporting staff in the ED to care effectively for patients who are dying whether from acute or non-acute causes is paramount.

\section{P-197 THE IMPACT OF A HOSPITAL BASED, VOLUNTEER-LED END OF LIFE SERVICE ON STAFF WELLBEING}

Kim Bonnar, Julia Bearne. Marie Curie, London, UK

\subsection{6/bmjspcare-2018-hospiceabs.222}

Background In 2014, a hospital in the South West of England and an end of life care charity introduced a service of specially trained volunteers to provide emotional and practical support to dying patients in hospital, and their friends and family.

Aims Alongside providing support to patients and families, the service was developed in acknowledgment of increasing pressure on staff. In particular, staff can have limited time to provide one-to-one support at the end of life (Nursing Standard/ Marie Curie survey, 2018).

Method To identify and understand any potential impacts of the service on NHS staff, nine semi-structured interviews were conducted. The sample included consultants, nurses, receptionists and chaplaincy staff to allow for the exploration of a range of different perspectives. A thematic analysis was conducted using the interview transcripts.

Results Three main staff benefit themes were identified: relieving feelings of professional guilt, being able to offer patients and families options, and the service's responsiveness and reliability. Staff spoke of challenges in giving patients their time on busy hospital wards. Interviewees spoke of the professional guilt experienced when they could not provide one-to-one support. The introduction of a reliable, well regarded volunteer service however allowed them to offer options for patients, alongside giving families opportunities for respite. In turn, staff described how the service helped to relieve feelings of professional guilt.

Conclusion This work suggests the service has a positive impact on staff, particularly in terms of relieving feelings of professional guilt. This is acutely relevant in a time of high 